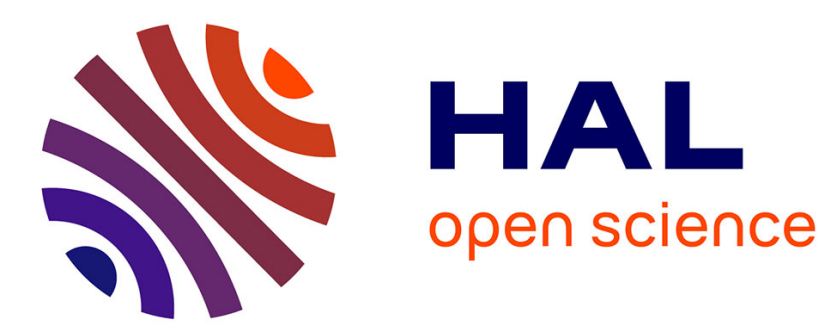

\title{
Is lifespan linked with developmental viability in Drosophila melanogaster?
}

\author{
Eric Le Bourg
}

\section{To cite this version:}

Eric Le Bourg. Is lifespan linked with developmental viability in Drosophila melanogaster?. Experimental Gerontology, 2021, pp.111583. 10.1016/j.exger.2021.111583 . hal-03379491

\section{HAL Id: hal-03379491 \\ https://hal.science/hal-03379491}

Submitted on 15 Oct 2021

HAL is a multi-disciplinary open access archive for the deposit and dissemination of scientific research documents, whether they are published or not. The documents may come from teaching and research institutions in France or abroad, or from public or private research centers.
L'archive ouverte pluridisciplinaire HAL, est destinée au dépôt et à la diffusion de documents scientifiques de niveau recherche, publiés ou non, émanant des établissements d'enseignement et de recherche français ou étrangers, des laboratoires publics ou privés. 
in Drosophila melanogaster?

6 E. Le Bourg (O) Centre de Recherches sur la Cognition Animale (CRCA), Centre de Biologie 7 Intégrative (CBI Toulouse), Université de Toulouse, CNRS, UPS, Toulouse, France

9 e-mail address: eric.le-bourg@univ-tlse3.fr

10 Orcid iD: https://orcid.org/0000-0001-5578-025X

Abstract

Long-lived lines of flies have been selected by reproduction at older ages and correlated 14 responses observed, and particularly whether development of flies was modified. Using these 15 selected lines or flies subjected to larval crowding of food restriction during development, two 16 studies have computed, among lines, a correlation between viability of eggs and larvae and mean

17 lifespan of adults: mean lifespan was longer when the viability was lower, showing a selection of

18 fittest flies. The present study correlates viability and mean lifespan observed during three decades

19 in a single wild-type strain. Contrary to the previous studies, a slight but not significant positive 20 correlation is observed, showing that lifespan can hardly increase when viability increases.

21 Therefore, it is not clear whether development and lifespan are linked, as hypothesised by some 22 authors. 


\section{Introduction}

Three centuries ago, Buffon (1749) wrote that, among species, duration of development is linked with lifespan. This idea has been confirmed by showing that species are spread on a continuum (Stearns, 1983) with, on one side, short-lived species with a small body size, a short gestation, maturing quickly, and giving birth at short intervals to many offspring (e.g. mice and rats), and, on the other side, species with the opposite life-history strategy (e.g. elephants or primates).

Regarding, within a species, the relationship between development and ageing, Lints (1988) reviewed the developmental theory of ageing stating that "some genes affect both traits pleiotropically, or that genes affecting both characters are closely linked". Studies of Lints and Lints (1971) making to vary environmental conditions during development of Drosophila melanogaster flies seemed to confirm this statement, showing a negative relationship between growth rate of larvae and lifespan, but Lints (1988) concluded that Economos and Lints (1984, 1986) eventually showed that there was "an optimal growth rate on both sides of which lifespan decreased".

In addition, many studies have selected long-lived lines of flies by reproduction at older ages and observed correlated responses and particularly whether development was modified. Reviewing studies measuring in long-lived and control lines developmental time and viability of flies, i.e. the percentage of eggs reaching adulthood, Wit et al. (2013) reported that any outcome could be observed. These results could allow to conclude that there is no clear link between development and mean lifespan of flies, but the only study (Buck et al., 2000) that computed a correlation between the viability and mean lifespan of selected lines seemed to point in another direction (Fig. 1). Buck et al. (2000) reported that mean lifespan decreased when viability increased in the $65-90 \%$ range, but did not indicate whether they used the longevity of males, females, or of both sexes combined. In flies subjected to larval crowding or food restriction during development, Zwaan et al. (1991) also reported a lower mean lifespan, in each sex, when viability increased in the $60-90 \%$ range. A high viability means that most of larvae, even the poorly fit ones, reach the adult stage. These flies could have a low lifespan and this could explain the negative relationship between viability and mean lifespan of the lines. As emphasised by Zwann et al. (1991), one can hypothesise that, "if viability is decreased, only the fittest individuals survive to adults (viability selection) and this increase in mean fitness becomes evident in increased adult longevity".

Obviously, these studies do not show that, at the individual level, there is a link between viability and lifespan because viability is measured in groups and not at the individual level. In human beings, the developmental origins of adult health and disease (DOHaD) theory explains that early life events, including in utero, can have major consequences in the adult and even at old age 
(reviews in Vaiserman 2019).

The purpose of this paper is to confirm or not the results of Buck et al. (2000) and Zwaan et al. (1991) by correlating viability and mean lifespan. The same wild-type strain was used during three decades and viability was observed for the very rearing groups used to observe lifespan in various experiments, all these groups living in very similar conditions, by controlling the age of parents and larval crowding. Eggs were transferred into vials, making possible to know the viability, developmental duration of flies, and the sex-ratio. In addition, larvae developed without larval crowding on a fresh medium, not used by other flies, and thus with no wastes of previous larvae or flies. For instance, urea, a toxic waste of larvae, which decreases viability and increases development duration (Botella et al. 1985), increases in crowded cultures (Henry et al. 2018). It has been shown that males and females developing in larval crowding conditions that emerged 3 days after the first ones had a lower weight and lifespan, and females had a lower fecundity measured once at young age (Lushchak et al., 2019): in all experiments reported below flies emerged 9-10 days after egg-laying.

\section{Material and methods}

The viability of the wild-type strain Meyzieu, caught at the end of the 1970s near the city of Lyon (France) was observed from 1988 to 2016 at $25^{\circ} \mathrm{C}$ in nearly 800 weeks (see the whole results in Le Bourg, 2021a). Groups with a very low viability (see Fig. 1 in Le Bourg, 2021a) were however not used to observe lifespan. Flies used in the present article were the control groups of several articles observing the effect of various factors on lifespan (Le Bourg, 2007, 2010, 2011, 2012, 2021b; Le Bourg and Lints, 1989; Le Bourg and Médioni, 1991; Le Bourg et al., 2000, 2002, 2015; Le Rohellec and Le Bourg, 2009), and were subjected to the very same rearing conditions (see below). The mean viability in the present study was 74.42\% (26 groups, range: $41.37-87.09 \%$ ). The mean lifespan of males was $46.09 \pm 1.02$ days (26 groups, range of means: 35.24-53.76 days), and that of females $52.37 \pm 1.27$ days (only 25 groups, females being not used in one experiment, range of means: 38.39-65.22 days). The number of harvested eggs in each group was in the 7002975 range. The number of flies in the longevity experiments was in the 40-130 range, depending on experiments.

In order to obtain the parents of the experimental flies, flies were allowed to lay eggs for one night in a bottle containing the medium (agar, sugar, corn meal and killed yeast) containing a mould inhibitor (para-hydroxymethyl-benzoic acid) and enriched with live yeast at the surface of the medium. This medium was used in all experiments. Flies emerging 9-10 days after egg-laying were 
transferred to fresh bottles: they are the parents of the experimental flies. Experimental flies were obtained as follows: eggs laid by ca. 5 day-old parents during one night on a Petri dish containing the medium coloured with charcoal were transferred by batches of 25 into $80 \mathrm{ml}$ glass vials. At emergence, flies were transferred in groups of 15 virgin flies of the same sex into $20 \mathrm{ml}$ polystyrene vials. Flies lived at $25^{\circ} \mathrm{C}$ (LD: $\left.12-12\right)$ at the Earth gravity level $(1 \mathrm{~g})$ and were transferred twice a week to new vials. To sum up, all groups of flies of the strain used in this article were subjected to the very same conditions. In such conditions, one can expect that viability and lifespan can vary among groups of flies because of random variations, showing a relationship between these traits if it indeed exists. However, a caveat is that, obviously, changes did occur between 1988 and 2016. The stocks of agar, sugar, corn meal, killed yeast were renewed when they were exhausted, and new live yeast was bought very often, as it cannot be used for a long time, even if kept at $4^{\circ} \mathrm{C}$. In addition, even if the temperature was always the same, different incubators could be used. Therefore, "very same conditions" should not be understood as meaning that all things were equal for three decades, but simply that care was taken to use similar rearing conditions: temperature, larval density, age of parents of experimental flies, transfers to new vials.

\section{Results and discussion}

Figure 2 shows the relationship between viability and lifespan. In each sex, the correlation is positive but not significant $(\mathrm{r}=0.371, \mathrm{n}=26$ in males, and $\mathrm{r}=0.282, \mathrm{n}=25$ in females). Pooling the two sexes, as Zwaan et al. (1991) did, made it became just significant $(r=0.283, p=0.0440, n=$ 51). These results thus show hardly a positive correlation between viability and mean lifespan, but in no case that longevity increased when viability decreased, contrary to the results of Buck et al. (2000) and Zwaan et al. (1991). However, a significant correlation was observed in this last study only if both sexes were pooled, the effect being marginally significant in each sex (Fig. 1). The present results show that viability does not help to predict lifespan of flies able to reach the adult stage. Observing individual durations of development and lifespans could allow to know whether development is linked to lifespan at the individual level, but a previous study of Mayer and Baker (1984) only showed a negligible relationship between these traits in both sexes, if any.

One of the strengths of the present study is that viability and lifespan were observed on the same groups and that the rearing conditions were the same for all groups during nearly three decades. One could thus expect that variation of viability and lifespan is linked to random environmental variation and possibly to genetic drift. For instance, larval crowding is not controlled in the stocks of flies kept in bottles for years, if not decades, and this could have an effect on 
126 lifespan. Lints et al. (1989) showed lifespan variations during a 4-year period in a single strain and

127 were unable to explain them. Could the discrepancy between the present results and those of Buck 128 et al. (2000) and Zwaan et al. (1991) be explained by the fact that these authors manipulated 129 developmental conditions, by modifying larval density or food quantity (Zwaan et al., 1991), or age 130 at reproduction (Buck et al., 2000)? Indeed, the procedure of the present article is similar to that of 131 Mayer and Baker (1984) who, "instead of perturbing the systems of development and aging, ... 132 attempted to observe them in a "free running" state by minimizing stresses known to influence the 133 duration of development or the length of imaginal life span".

134 For the time being, it seems possible to conclude that, when flies develop in controlled 135 conditions, there is no clear relationship between viability and mean lifespan, but these results do 136 not allow concluding that there is not any link between development and ageing, particularly in 137 human beings.

In humans, one of the first studies showing the importance of early-life events was that of 139 Barker and Osmond (1986) who reported that the 1968-1978 ischaemic heart disease prevalence in 140 various sites of UK, differing by their wealth, was strongly linked to infant mortality in 1921-1925 141 in the same sites. Because both infant mortality in 1921-1925 and ischaemic heart disease 142 prevalence in the 1970s were higher in lower socio-economic groups, the authors suggested that 143 "the geographical distribution of ischaemic heart disease in England and Wales reflects variations in 144 nutrition in early life". In a subsequent study, Osmond et al. (1993) showed that low birth weight is 145 linked to death from cardiovascular disease in both sexes. It is thus not surprising that women 146 suffering from the 1944 Dutch winter famine during their mid-to late gestation gave birth to low147 weight babies, and, in addition, that famine during early gestation, even if birth weight was normal, 148 was also associated with cardio-vascular disease at middle age (review in Preston et al., 2018) and 149 death rate in women, but not in men (van Abeelen et al., 2012). On the whole, early-life events, and 150 particularly foetal nutrition, can have long-lasting adverse consequences in humans (review in 151 Vaiserman et al., 2018) and results in animal models are not at variance (Tarry-Adkins and Ozanne 152 2017).

\section{Funding details}

This research did not receive any specific grant. 
158 Figure 1. Relationship between viability and mean lifespan in Buck et al. (2000) and Zwaan et 159 al. (1991). Lifespan is observed, respectively at 25 and $29^{\circ} \mathrm{C}$, but the development is done at $25^{\circ} \mathrm{C}$ 160 in both studies. For the Buck et al.'s (2000) study, lifespan data were determined from Figure 5 and 161 viability ones were extracted from Table 2. For the Zwaan et al.'s (1991) study, data were extracted

162 from Tables 3, 4, 5, 7. The correlation is not significant in Zwaan et al. (1991) if sexes are analysed 163 separately, but the authors pooled sexes, which made the correlation being significant (in the figure: $164 \mathrm{r}=-0.546, \mathrm{p}=0.0057, \mathrm{n}=24$; in Zwaan et al. (1991): $\mathrm{r}=-0.59, \mathrm{p}<0.01)$. The correlation 165 reported by Buck et al. (2000) is $\mathrm{r}=-0.791(\mathrm{r}=-0.794$ in the figure).

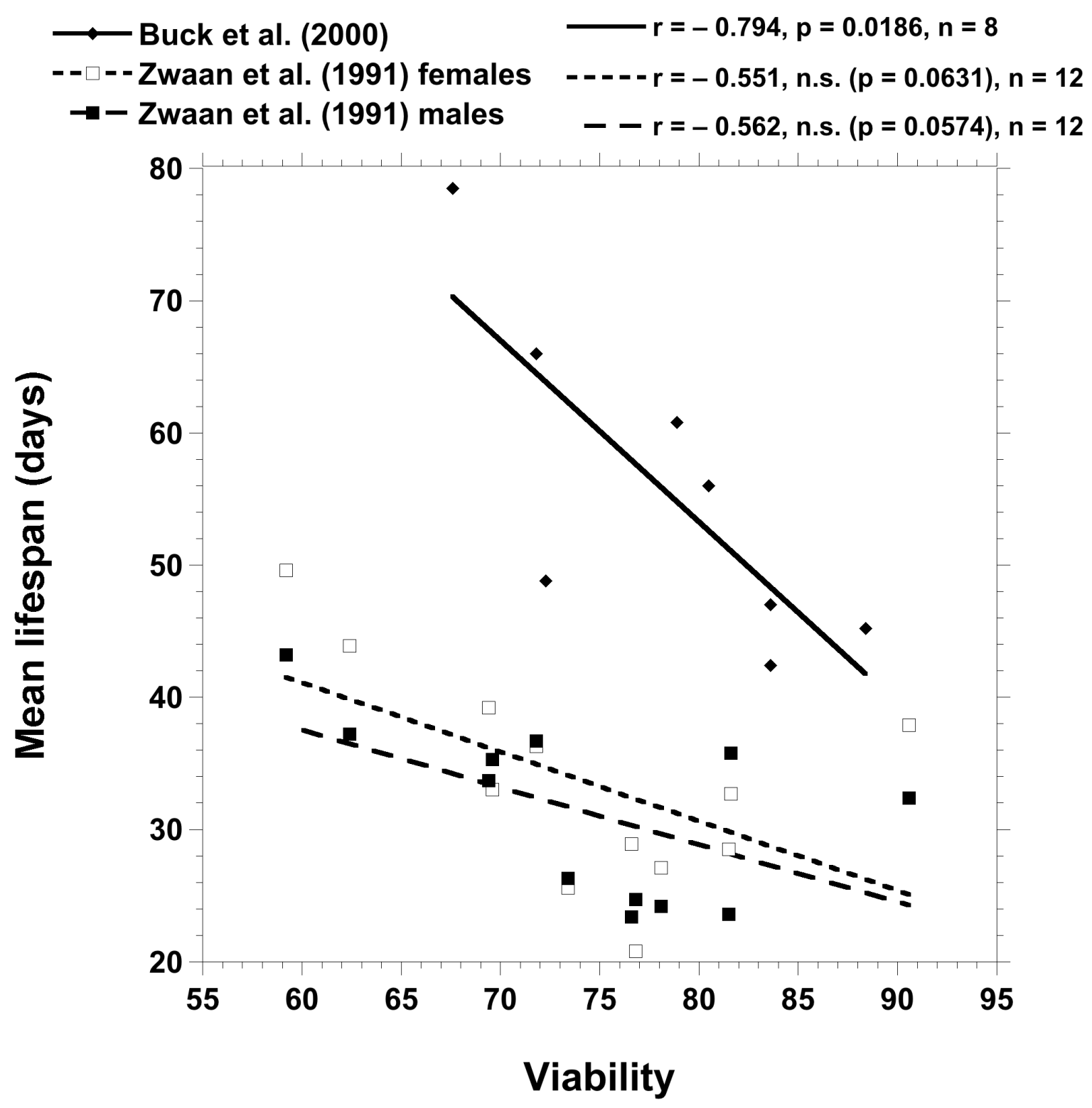


166 Figure 2. Relationship between viability and mean lifespan in the Meyzieu wild-type strain in

167 flies observed during three decades.

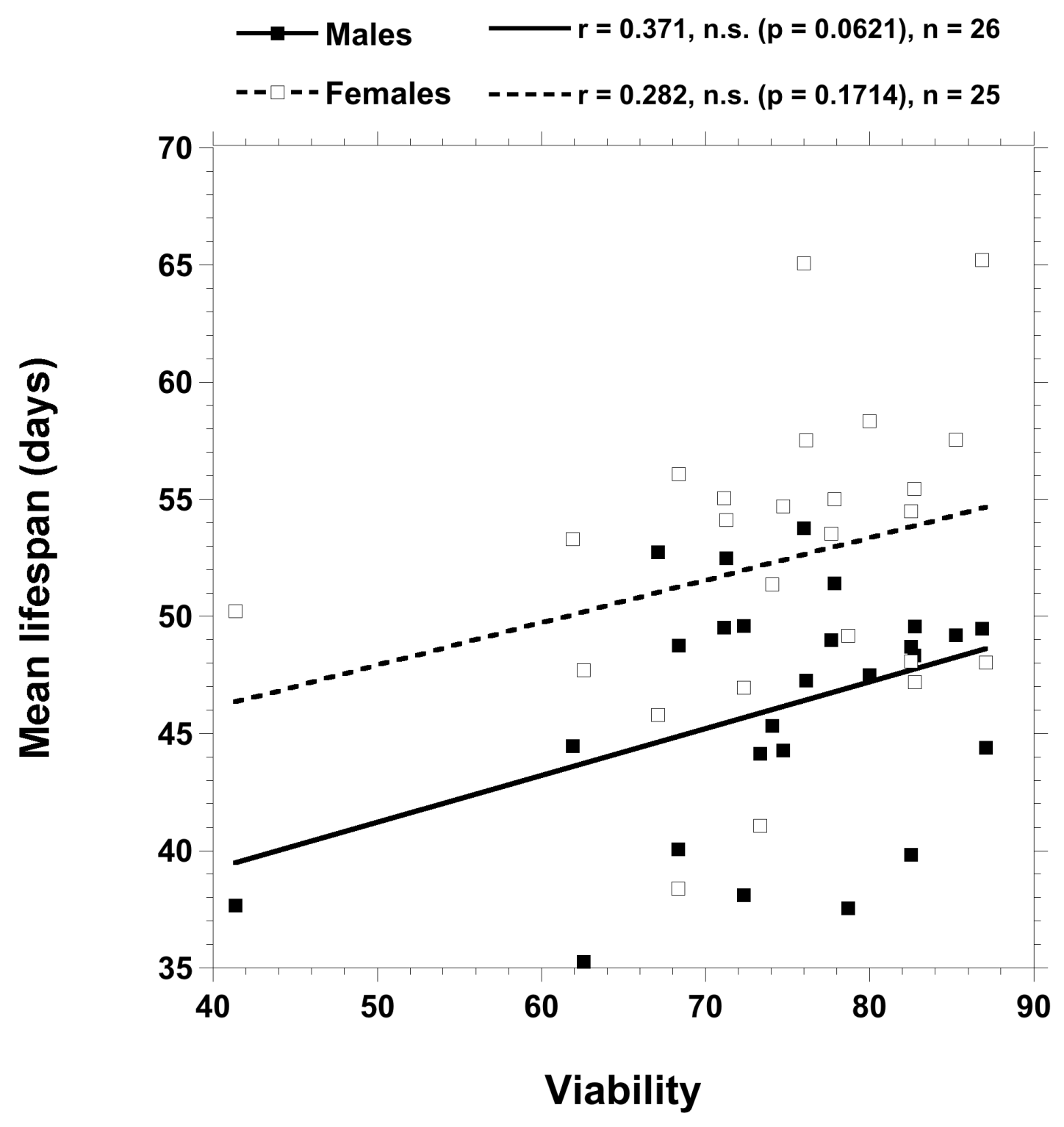




\section{References}

van Abeelen, A.F., Veenendaal, M.V., Painter, R.C., De Rooij, S.R., Dijkgraaf, M.G., Bossuyt, P.M., Elias, S.G., Grobbee, D.E., Uiterwaal, C.S., Roseboom, T.J., 2012. Survival effects of prenatal famine exposure. Am. J. Clin. Nutr. 95, 179-183. https://doi.org/10.3945/ajen.111.022038

Barker, D.J.P., Osmond, C., 1986. Infant mortality, childhood nutrition, and ischaemic heart disease in England and Wales. Lancet 327, 1077-1081. https://doi.org/10.1016/S0140-

\section{$\underline{6736(86) 91340-1}$}

Botella, L.M., Moya, A., Gonzalez, M.C., Ménsua, J.L., 1985. Larval stop, delayed development and survival in overcrowded cultures of Drosophila melanogaster: effect of urea and uric acid. J. Insect Physiol. 31, 179-185. https://doi.org/10.1016/0022-1910(85)90118-0

Buck, S., Vettraino, J., Force, A.G., Arking, R., 2000. Extended longevity in Drosophila is consistently associated with a decrease in developmental viability. J. Geront. Biol. Sci. 55A, B292-B301. https://doi.org/10.1093/gerona/55.6.B292

Buffon, G.L., 1749. Histoire naturelle de l'Homme (Natural history of Man). Imprimerie royale, Paris (English translation: Natural history, general and particular, Strahan W and Cadell T, London, 1785). https://gallica.bnf.fr/ark:/12148/bpt6k1067226x

Economos, A.C., Lints, F.A., 1984. Growth rate and life span in Drosophila. II. A biphasic relationship between growth rate and life span. Mech. Ageing Dev. 27, 143-151. https://doi.org/10.1016/0047-6374(84)90039-3

Economos, A.C., Lints, F.A., 1986. Developmental temperature and life span in Drosophila melanogaster I. Constant developmental temperature: evidence for physiological adaptation in a wide temperature range. Gerontology 32, 18-27. https://doi.org/10.1159/000212761

Henry, Y., Renault, D., Colinet, H., 2018. Hormesis-like effect of mild larval crowding on thermotolerance in Drosophila flies. J. Exp. Biol. 221 pii:jeb169342. https://doi.org/10.1242/jeb.169342

Le Bourg, E., 2007. Hormetic effects of repeated exposures to cold at young age on longevity, aging and resistance to heat or cold shocks in Drosophila melanogaster. Biogerontology 8 , 431-444. https://doi.org/10.1007/s10522-007-9086-6

Le Bourg, E., 2010. Combined effects of suppressing live yeast and of a cold pretreatment on longevity, aging and resistance to several stresses in Drosophila melanogaster. Biogerontology 11, 245-254. https://doi.org/10.1007/s10522-009-9250-2

Le Bourg, E., 2011. A cold stress applied at various ages can increase resistance to heat and fungal infection in aged Drosophila melanogaster flies. Biogerontology 12, 185-193. 
https://doi.org/10.1007/s10522-010-9309-0

203

Le Bourg, E., 2012. Combined effects of two mild stresses (cold and hypergravity) on longevity, behavioral aging, and resistance to severe stresses in Drosophila melanogaster. Biogerontology 13, 313-328. https://doi.org/10.1007/s10522-012-9377-4

Le Bourg, E., 2021a. Neglecting larval rearing conditions in Drosophila melanogaster can negatively impact research on ageing. Biogerontology 22, 369-373. https://doi.org/10.1007/s10522-021-09917-y

Le Bourg, E., 2021b. A mild heat stress increases resistance to heat of dFOXO Drosophila melanogaster mutants but less in wild-type flies. Biogerontology 22, 237-251. https://doi.org/10.1007/s10522-021-09914-1

Le Bourg, E., Gauthier, T., Colinet, H., 2015. Feeding on frozen live yeast has some deleterious effects in Drosophila melanogaster. Exp. Geront. 69, 202-210. http://dx.doi.org/10.1016/j.exger.2015.06.019

Le Bourg, E., Lints, F.A., 1989. Hypergravity and ageing in Drosophila melanogaster. 2. Longevity. Gerontology 35, 244-252. https://doi.org/10.1159/000213033

Le Bourg, E., Médioni, J., 1991. Food restriction and longevity in Drosophila melanogaster. Age Nutr. 2, 90-94.

Le Bourg, E., Minois, N., Bullens, P., Baret P., 2000. A mild stress due to hypergravity exposure at youngage increases longevity in Drosophila melanogaster males. Biogerontology 1, 145-155. https://doi.org/10.1023/A:1010043914016

Le Bourg, E., Valenti, P., Payre, F., 2002. Lack of hypergravity-associated longevity extension in Drosophila melanogaster flies overexpressing hsp 70. Biogerontology 3, 355-364. https://doi.org/10.1023/A:1021367800170

Le Rohellec, M., Le Bourg, E., 2009. Contrasted effects of suppressing live yeast from food on longevity, aging and resistance to several stresses in Drosophila melanogaster. Exp. Geront. 44, 695-707. https://doi.org/10.1016/j.exger.2009.08.001

Lints, F.A., 1988. Genetics, in: Lints, F.A., Soliman, M.H. (Eds.) Drosophila as a model organism for ageing studies. Blackie, Glasgow, pp. 99-118. https://doi.org/10.1007/978-1-4899-2683-8

Lints, F.A., Lints, C.V., 1971. Influence of preimaginal environment on fecundity and ageing in Drosophila melanogaster hybrids - III. Developmental speed and life-span. Exp. Geront. 6, 427-445. https://doi.org/10.1016/0531-5565(71)90022-2

Lints, F.A., Lints, C.V., Bullens, P., Bourgois, M., Delincé, J., 1989. Unexplained variations in life span of the Oregon-R strain of Drosophila melanogaster over a four-year period. Exp. Geront. 24, 265-271. https://doi.org/10.1016/0531-5565(89)90017-X 
236

Lushchak, O.V., Karaman, H.S., Kozeretska, I.A., Koliada, A.K., Zabuga, O.G., Pisaruk, A.V., Koshel, N.M., Mechova, L.V., Inomistova, M.V., Khranovska, N.M., Vaiserman, A.M., 2019. Larval crowding results in hormesis-like effects on longevity in Drosophila: timing of eclosion as a model. Biogerontology 20, 191-201. https://doi.org/10.1007/s10522-018-9786-0

Mayer, P.J., Baker, G.T., III, 1984. Developmental time and adult longevity in two strains of Drosophila melanogaster in a constant low-stress environment. Mech. Ageing Dev. 26, 283298. https://doi.org/10.1016/0047-6374(84)90101-5

Osmond, C., Barker, D.J.P., Winter, P.D., Fall, C.H.D., Simmonds, S.J., 1993. Early growth and death from cardiovascular disease in women. Brit. Med. J. 307, 1519-1524. https://doi.org/10.1136/bmj.307.6918.1519

Preston, J.D., Reynolds, L.J., Pearson, K.J, 2018. Developmental origins of health span and life span: a mini-review. Gerontology 64, 237-245. https://doi.org/10.1159/000485506

Stearns, S.C., 1983. The influence of size and phylogeny on patterns of covariation among lifehistory traits in the mammals. Oikos 41, 173-187. https://doi.org/10.2307/3544261

Tarry-Adkins, J.L., Ozanne, S.E, 2017. Nutrition in early life and age-associated diseases. Ageing Res. Rev. 39, 96-105. https://doi.org/10.1016/j.arr.2016.08.003

Vaiserman, A., (Ed.) 2019. Early life origins of ageing and longevity. Springer, Dordrecht, 310 pp. https://doi.org/10.1007/978-3-030-24958-8

Vaiserman, A., Koliada, A., Lushchak, O. 2018. Developmental programming of aging trajectory. Ageing Res. Rev. 47, 105-122. https://doi.org/10.1016/j.arr.2018.07.007

Wit, J., Sarup, P., Lupsa, N., Malte, H., Frydenberg, J., Loeschcke, V., 2013. Longevity for free? Increased reproduction with limited trade-offs in Drosophila melanogaster selected for increased life span. Exp. Geront. 48, 349-357. https://doi.org/10.1016/j.exger.2013.01.008

Zwaan, B.J., Bijlsma, R., Hoekstra, R.F., 1991. On the developmental theory of ageing. I. Starvation resistance and longevity in Drosophila melanogaster in relation to pre-adult breeding conditions. Heredity 66, 29-39. https://doi.org/10.1038/hdy.1991.4 